
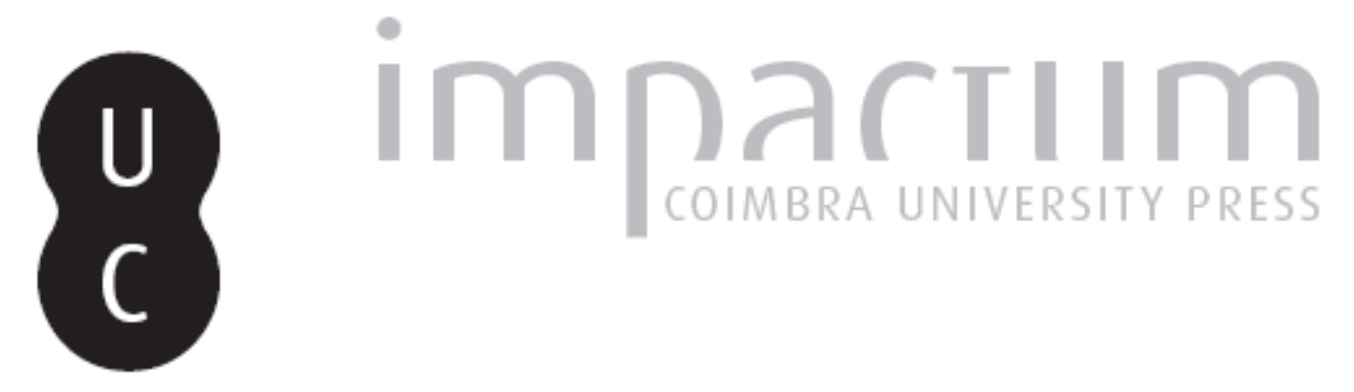

\title{
O coro na Antígona de António Pedro
}

\section{Autor(es): Ventura, Cidália}

Publicado por: Faculdade de Letras da Universidade de Coimbra

URL persistente:

URI:http://hdl.handle.net/10316.2/38985

DOI:

DOI:http://dx.doi.org/10.14195/0870-4112_1_10

Accessed : $\quad$ 26-Apr-2023 09:42:42

A navegação consulta e descarregamento dos títulos inseridos nas Bibliotecas Digitais UC Digitalis, UC Pombalina e UC Impactum, pressupõem a aceitação plena e sem reservas dos Termos e Condições de Uso destas Bibliotecas Digitais, disponíveis em https://digitalis.uc.pt/pt-pt/termos.

Conforme exposto nos referidos Termos e Condições de Uso, o descarregamento de títulos de acesso restrito requer uma licença válida de autorização devendo o utilizador aceder ao(s) documento(s) a partir de um endereço de IP da instituição detentora da supramencionada licença.

Ao utilizador é apenas permitido o descarregamento para uso pessoal, pelo que o emprego do(s) título(s) descarregado(s) para outro fim, designadamente comercial, carece de autorização do respetivo autor ou editor da obra.

Na medida em que todas as obras da UC Digitalis se encontram protegidas pelo Código do Direito de Autor e Direitos Conexos e demais legislação aplicável, toda a cópia, parcial ou total, deste documento, nos casos em que é legalmente admitida, deverá conter ou fazer-se acompanhar por este aviso.

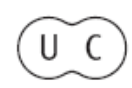




\section{Culturas em Diálogo}

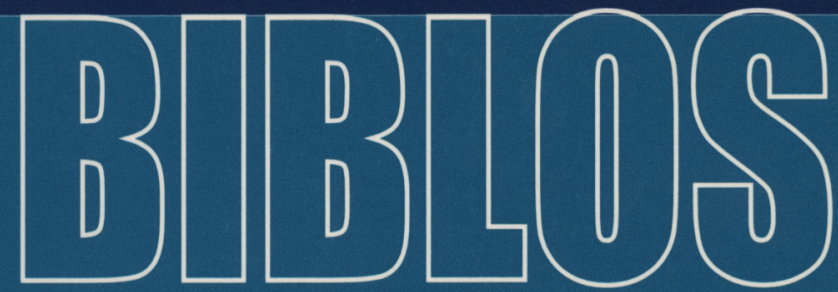


O Coro na Antígona de Ant ónio Pedro

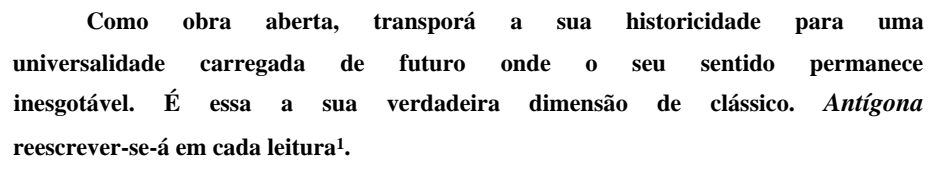

Maria do Céu Fialho

É, efectivamente, uma obra aberta a Antígona de Sófocles ${ }^{2}$. A prová-lo estão as inúmeras reescritas do mito, de forma mais ou menos livre, mais ou menos criativa. Não é aqui lugar para enumerá-las, mas mencionar apenas a de António Pedro, a que ele próprio chamou Antígona - Glosa nova da tragédia de Sófocles ${ }^{3}$.

Importa referir que António Pedro escreve a sua Glosa nos finais de $1953^{4}$ e leva-a à cena a 18 de Fevereiro de 1954 , no Teatro de $\mathrm{S}$.

1 M C. Fialho, 'Sobre o trágico em Antígona de Sófocles', in Estudos sobre Antígona (Lisboa, Editorial Inquérito 2000) 30.

2 Sófocles, Antígona. Tradução de M. H. Rocha Pereira (Coimbra, INIC 1987).

2 A. Pedro, ‘Antígona - Glosa nova da tragédia de Sófocles', Teatro Completo

(Lisboa, Imprensa Nacional Casa da Moeda 1977).

4 Passados 50 anos, o T.E.P. não esqueceu o homem que o transformou, António Pedro, e levou novamente à cena a sua Antígona - Glosa nova da tragédia de Sófocles, encontrando assim a melhor forma de homenagear o homem de teatro e a obra imortal do dramaturgo grego, Sófocles. Estreou a 24 de Maio de 2003 e esteve em cena até 18 de Junho, no Auditório Municipal de Gaia com encenação de Norberto Barroca, actual Director artístico. É lícito dizer que, mais uma vez, em tempos difíceis para a cultura, o T.E.P. deu mostras de grandeza ao festejar os seus 50 anos com o programa que apresenta. Antígona lutou pelos seus ideais, assim o T.E.P. tem lutado pelo sonho do teatro e, como dizia Antígona na peça de A.P.: "Só o impossível vale a pena!...”, o Teatro Experimental do Porto continua a lutar pelo que se julga ainda ser impossível. 
João, no Porto. Nesta época, decorriam já mais de vinte anos de ditadura e autoritarismo, protagonizados pelo Estado Novo na figura de Salazar e pela forte actuação da Polícia Política. Ocorrem, nesta altura, várias tentativas tímidas de combater o regime, a União Nacional está manifestamente em crise ${ }^{5}$; no entanto, todas as manifestações abertas contra o regime eram punidas e a censura não deixava vir a lume qualquer acto cultural que não se manifestasse a favor desse mesmo regime. Culturalmente viviam-se os chamados «anos de chumbo», reveladores de uma clara acomodação e apatia. No teatro, predominavam os dramas burgueses apagados e sem vida.

António Pedro encontrou no Porto o ambiente ideal para dar asas à sua ideia de arte viva e criativa, uma vez que esta cidade vivia um "clima cultural de independência" e talvez até de uma certa irreverência. ${ }^{6}$ É o próprio António Pedro que diz: "De Moledo, descobri o Porto. Foi uma grande descoberta. O Porto é uma cidade de província, mas de uma província que pertence à Europa".

Nada melhor do que o palco seria o subterfúgio para elevar o grito da liberdade por que o povo tanto ansiava e não tinha e, já que o palco da vida não deixava sonhar, António Pedro levou o sonho ao palco do Teatro de S. João do Porto, através de Antígona. Assim, a sua peça tem um objectivo declaradamente político, objectivo esse anunciado logo nas palavras do Io Velho do Coro: "a tragédia da liberdade."

5 A título de exemplo, podemos referir que «em 19 de Setembro de 1950 aparecia a X Comissão Executiva (...), permanecendo no exercício de funções cerca de sete anos. A tarefa principal seria a preparação de novo Congresso, marcado para Maio de 1951 (...). Aí se devia discutir a revisão dos Estatutos, mas a morte do Presidente Óscar Carmona (18 de Abril de 1951) fez adiar a reunião. Aproveitando essa circunstância, a corrente de opinião monárquica tentou introduzir a questão do regime, através de uma metodologia que Salazar havia de classificar como "tentativa de Golpe de Estado Constitucional.» - V. Moreira 'O sistema jurídico-constitucional do «Estado Novo», in História de Portugal XII (Amadora. Clube Internacional do Livro) 216-217.

6 O advogado e escritor António Ramos de Almeida escreve, em 24 de Maio de 1953, num artigo publicado no Diário de Lisboa, pouco antes da apresentação do TEP: «Realmente, o Porto viveu sempre um clima cultural de independência, que se caracteriza na sua essência por uma espécie de autodidactismo irreverente e ousado, em combate permanente com as correntes oficiais e oficiosas, modeladas pela tradição escolástica que tem resistido a tudo, apenas sofrendo aqui e ali de meras deturpações formais ou casuísticas. (...) Ora, o clima cultural do Porto permanece, insiste, revigorando-se actualmente, alargando-se em novas e amplas perspectivas (...).»

Faculdade de Letras Universidade de Coimbra 
O texto de Sófocles servia perfeitamente os seus intentos, já que exprimia esse tal grito de revolta, essa tal reivindicação da liberdade, suscitada pelo contexto político que se vivia. Além disso, seria fácil passar pela censura, pois o texto clássico não seria acessível ao grande público. Antígona foi, então, um instrumento camuflado de luta contra o regime absoluto, ditatorial e tirânico do Estado Novo. Mantendo o fundo trágico da obra, António Pedro condenou os "vícios e erros do homem, com a defesa das virtudes humanas, impondo como advertência salutar a acusação da própria consciência e o castigo inexorável aos que manejam o orgulho e a tirania, como arma que fere; mas não vence". ${ }^{7}$

Esta Glosa nova da tragédia de Sófocles apresenta-nos algumas inovações relativamente ao texto clássico, como a introdução da personagem do Encenador, que fornece ao espectador moderno alguns dados sobre a tragédia e o prepara para a viagem ao fabuloso mundo do teatro, e da criadita Artemísia, que "é decorativa e faz falta ao nosso hábito de comédia burguesa.(...) Esta aparece como criadinha que limpa o pó no começo dos primeiros actos" e vem "dar a primeira réplica a Antígona...". Outra grande novidade de António Pedro está no Coro. do qual este trabalho se ocupará.

No meu entender, o autor resolve admiravelmente o problema do Coro. O público não estaria preparado para digerir as grandes tiradas, em linguagem um tanto ou quanto pesada, dos quinze anciãos de Tebas presentes na Antígona original. Assim vai reduzi-lo a três Velhos, simplifica-lhe a linguagem e reduz-lhe também o tamanho das falas. Apesar de não lhe conferir o papel activo que tem em Sófocles, podemos continuar a considerá-lo uma personagem que interage no drama através de alguns diálogos, opiniões e conselhos que, salvo algumas excepções, correspondem aos temas abordados em Sófocles. Para garantir este efeito, António Pedro mantém um Coro de Velhos, a idade apropriada à voz do bom senso, que o Coro também pretende ser.

A maior novidade será a nível estrutural; se há contaminado a nível temático, ela já não será tão evidente na forma. Não temos na Antígona de António Pedro a tradicional e clássica divisão das partes corais em párodo seguido de estásimos, cujo final servia também para introduzir uma nova personagem em cena. O dramaturgo moderno, conhecedor do seu tempo e das sensibilidades do seu público, dá uma alma nova ao drama e introduz a frescura de uma "criadinha", Artemísia,

\footnotetext{
7 Comércio do Porto, 19/02/1954.
} 
que vai substituindo o Coro na sua função de fazer avançar a acção, dando a deixa a uma nova personagem em cena. Na realidade, esta personagem, como diz o Io Velho do Coro, "não é da tragédia grega." Como já vimos, é pela boca do Encenador que ficamos a saber que tem uma função "decorativa", que faz falta ao "hábito da comédia burguesa" e que "aparece como a criadinha que limpa o pó no começo dos primeiros actos”. No entanto, ali não há pó para limpar e Artemísia serve para "dar a primeira réplica a Antígona, quando ela chegar". E assim acontece; é, efectivamente esta figura, aparentemente decorativa, que dá a primeira réplica a Antígona (p. 268):

Antígona:

\{para Artemísia) Viste Isménia, minha irmã?

Artemísia:

Bom dia, Antígona. Que os deuses te protejam. Pareces excitada, fora de ti.

Encontramos depois Artemísia, no início do segundo acto, a anunciar, aflita, a chegada de Antígona que trazem, presa, à presença de Creonte (p. 289):

Artemísia:

Antígona! Antígona! Trazem presa a filha do Rei Édipo à presença de Creonte!

Em Sófocles, este anúncio é feito pelo Coro, no final do Io estásimo (Ant. 377, 383):

\footnotetext{
Hesito ao olhar o portento divino,

mas, se eu sei, como negar

que esta jovem é Antígona?

Do desgraçado Édipo, ó filha,

que aconteceu? Ah! Não te trouxeram

porque as régias leis infringisses

e por louca te prendessem?
}

Sensivelmente a meio do segundo acto, o diálogo entre Artemísia e o Encenador é elucidativo. A jovem expressa o seu desalento pela menoridade do papel: "Eu assim não sei realmente o papel que tenho! Não sei para que é que me meteram na peça. Sempre que chega a minha vez de intervir, põem-se a filosofar e estragam inteiramente a 
minha presença"(p. 303). As palavras de Artemísia levantam já um pouco o véu à principal função do Coro nesta peça ao dizer "põem-se a filosofar". É certo que o Coro não faz avançar a acção, para isso foi criada Artemísia; o Coro, o que faz essencialmente é comentar, mesmo quando entra em diálogo com outras personagens. São as afirmações seguintes do Encenador que nos vêm confirmar exactamente esta ideia: "tu és o contrário dos velhos. Eles comentam, tu preparas a acção. Por isso eles são velhos e tu és jovem e bonita". Ora, comentar e preparar a acção seriam dois atributos do Coro grego. Aqui, a juventude dinâmica e activa, representada por Artemísia, prepara a acção; a velhice, pela experiência de vida que acarreta, reflecte, opina e recrimina.

O Encenador dá liberdade e independência à criadita que, neste acto, dá o mote a Hémon e, para surpresa nossa, confessa a sua paixão pelo filho de Creonte. Finalmente, no início do terceiro acto, é através do seu diálogo com Creonte que se anuncia a chegada de Tirésias (p. 3 15): Creonte:

Leva essas flores e deita-as fora! Não cabe nenhuma mostra de alegria onde só há desolação. Chamaram Tirésias?

Artemísia:

Foi um mensageiro chamá-lo e diz que ele vem já. Levo então as flores. Parece que o cego estava numa disposição terrível!

Na tragédia de Sófocles, Flémon entra em cena no final do $2^{\circ}$ estásimo, depois de o Coro proferir estas palavras (Ant. 626, 630):

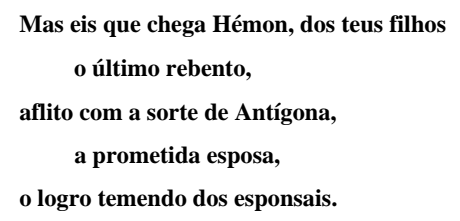

Por sua vez, Tirésias surge depois de o Coro entoar o $4^{\circ}$ estásimo.

Como vemos, o dramaturgo divide as funções do Coro grego: atribui uma parte ao Coro de Velhos e outra a Artemísia, tornando a peça muito mais agradável e atractiva para o público seu contemporâneo.

Voltemos ao Coro. Em Sófocles, a sua primeira aparição é no párodo onde se regozija pela paz na cidade, apela à protecção de Baco e, no final, anuncia a chegada de Creonte. Na Antígona de António Pedro, o Coro surge a dialogar com o Encenador, no Prólogo. Logo aqui o Coro 
assume uma função que não tem em Sófocles e que, na minha opinião, é deveras interessante. Vejamos. O Coro português abre com esta frase: "De Sófocles não. Não são as palavras de Sófocles que vamos dizer". Ora, o Velho introduz propositadamente a questão da autoria das palavras que vão dizer, suscitando a resposta do encenador que "revela abertamente a liberalidade da agenda teórica e estética do encenador moderno".

Encenador:

Não serão. Mas as palavras têm, no teatro, muitíssimo pouca importância. Vamos representar uma Antígona, e foi Sófocles que inventou a Antígona, a tragédia de Antígona que não está nas suas palavras mas nas situações que desenvolvem, na acção que decorre entre um certo número de personagens que o poeta criou. (p. 259).

Reforça-se aqui a ideia de Antígona como obra aberta, não são as palavras que importam, mas os contextos em que são proferidas, não é a palavra que absorve exclusivamente este teatro, nem o define como espectáculo, o teatro deve pôr as palavras em situação. Daí que na nota inicial ao texto se diga que a "Grécia é apenas o pretexto cénico"; a acção passa-se agora na imaginação de cada um.

Ainda no prólogo, o Coro tem a função de apresentar as personagens que constam da tragédia e é também ele que alerta para a existência de Artemísia, referindo que ela não pertence à tragédia antiga. Mais uma vez, na boca do $3^{\circ}$ Velho, Antígona nos é apresentada como obra aberta e universal, cabendo em todos os tempos e todos os lugares, de acordo com as suas motivações e valores, pois as personagens são eternas (p. 260). Gradativamente, os três velhos do Coro vão-nos apontando os ingredientes da tragédia e, nessa sequência, o Coro vai agora informar-nos da sua intenção:

$03^{\circ}$ Velho:

A tragédia de quem se recusa a obedecer à lei em nome duma lei que é superior aos homens.

$02^{\circ}$ Velho:

Que é superior às circunstâncias em que os homens fazem certas leis.

O Io Velho:

A tragédia da liberdade.

É através destas palavras que podemos afirmar que esta tragédia é um instrumento de luta e de revolta, logo tem uma intencionalidade marcadamente política. 


\section{O CORO NA ANTÍGONA DE ANTÓNIO PEDRO}

Vem a propósito perguntar: não será também este coro um dos principais veículos de transmissão da mensagem política da peça? E o que tentaremos ver ao longo da sua análise.

Continuando no prólogo, é o Io Velho que nos inicia no tema do texto, ao identificar Creonte e ao informar como morreram Etéocles e Polinices (p. 261). Aproveitando a batalha que travaram entre si, o $2^{\circ}$ e $3^{\circ}$ Velhos exercem uma crítica que pode muito bem ser dirigida, primeiro a todos os tiranos que, cegos pelo poder, fazem a guerra (p.261) (não nos podemos esquecer de que se assistia ainda ao rescaldo do segundo grande conflito mundial), e depois, talvez uma crítica mais particularizada ao regime ditatorial do Estado Novo: “ A justiça é então uma ordem que se estabelece para os outros não terem razão?”.

Diferentemente do que acontece em Sófocles, o conflito não se patenteia logo com a chegada de Creonte $^{8}$, mas com a intervenção de vozes do povo anónimo (mais à frente falarei no papel destas vozes) que grita vivas ao rei, e com o Coro dos três anciãos. Estes constatam que não era necessário anunciar a paz, pois se a guerra acabou o que fica é a paz.

Nova intervenção do Coro, numa reflexão despoletada pela decisão de Antígona de sepultar o irmão. Para estes três velhos, Antígona pretende levar a cabo um acto de loucura, que a poderá conduzir à morte: esta é "um destino natural", "não se convida", "aceita-se quando vier" "e o mais tarde que for possível”(p. 270). Aqui a função do Coro é apenas comentar a atitude de Antígona, nada mais, uma vez que este tem consciência do que lhe poderá acontecer ao desobedecer à lei de Creonte.

As ideias expressas no párodo de Sófocles aparecem em António Pedro mais tarde, depois da primeira intervenção de Antígona com Ismena e da reflexão enunciada pelos velhos. À semelhança do coro grego, estes Velhos celebram a paz na cidade. Embora não esteja no lugar tradicional, esta intervenção coral é uma reescrita livre de Sófocles (p.273, 275), havendo mesmo um verso quase igual: "Zeus detesta a jactância dos fortes" a que corresponde em Sófocles "Zeus, o que abominava a vaidade de uma língua soberba" (Ant. 127, 128). Também aqui o Coro dá vivas ao rei Creonte, mas, tal como acontece em Sófocles,

8 A acção, na obra de Sófocles, inicia-se depois do párodo, com uma grande tirada de Creonte. Este convoca os cidadãos para os informar do édito que havia proclamado, proibindo a sepultura de Polinices: “...quanto a esse, proclamou-se nesta cidade que nem seria sepultado, nem pessoa alguma o lamentaria, mas se deixaria insepulto, e que o seu corpo, dado a comer aos cães $\mathrm{e}$ às aves de rapina, se havia de tornar um espectáculo vergonhoso." 
as suas palavras não são de concordância espontânea com o rei, parecem antes algo forçado. Aliás, no Coro de António Pedro é muito mais notório que este não está em sintonia com Creonte.

Quanto ao primeiro estásimo, também conhecido como "Ode ao Homem", aparece nesta peça dividido em duas partes, a primeira nas pp. 278 - 279 e a segunda nas pp. 284 - 286. A primeira parte está relacionada com o homem e a cidade, é um comentário crítico ao poder do Homem, a quem cabe permitir que as cidades se encham ou se esvaziem, cresçam ou sejam destruídas. Tudo depende da forma como usa o poder, pois a grandeza "não é outra coisa senão a ideia que dela se faz". É, no meu entender, um apontar o dedo disfarçado ao regime vivido na altura e à figura do próprio Salazar.

A segunda parte evidencia o lirismo do Coro e segue as ideias fundamentais do estásimo sofocleano. A superioridade do Homem, que é o maior mistério da natureza, é também aqui evidenciada, enumeram-se as suas conquistas, a sua capacidade para o sonho, a poesia e a música e a capacidade de "inventar os códigos e as leis". No entanto, termina com um aviso ao Homem: este não é omnipotente "só contra a morte não é capaz!" São as três últimas intervenções dos Velhos nesta ode que fazem a derradeira advertência ao Homem: este deve ser prudente e não ir além daquilo que lhe compete:

$02^{\circ}$ Velho:

E ai de ti!

Todos:

Ai de ti!

O 1o Velho:

Se te atreves àquilo de que não és capaz.

Estas palavras finais condensam toda a segunda antístrofe de Sófocles e serão, à primeira vista, um aviso ao Homem em geral; contudo parece-me terem um destino muito mais particular - Salazar e os homens do regime.

Assim termina o primeiro acto, dando lugar ao segundo, em que surge Antígona, aprisionada pelo soldado, tal como acontece na peça grega. Numa fala do $2^{\circ}$ Velho está bem patente uma crítica à polícia política da altura, a PIDE: "Para ser um bom polícia não é preciso ser inteligente. Basta ser mau como as ratoeiras" (p. 290). Ouvindo estas palavras, o Soldado pergunta "Quem é aquele senhor?", ao que Artemísia responde "É um dos velhos do coro. Não tem importância para a acção da 
peça. Continua" (p. 291), apontando, ao mesmo tempo, a função do Coro no drama.

À semelhança do Coro dos anciãos de Tebas, estes Velhos caracterizam também Antígona face à sua atitude:

O 10 Velho:

Inflexível.

O $3^{\circ}$ Velho:

Corajosa.

O 2o Velho:

Simples e dura, feita de aço, como seu pai!

$03^{\circ}$ Velho:

Seu pai, Creonte, que foi Édipo, rei de Tebas. sentado nesse trono.^

No entanto, este Coro não recrimina Antígona, como o de Sófocles, antes parece querer alertar Creonte para o seu destino final, seguindo os passos de Édipo. A maldição hereditária, que pode ser já aqui levemente abordada, deveria constar de um segundo estásimo entoado pelo Coro. Mas, na realidade, esse segundo estásimo é substituído por um diálogo entre o Encenador e os Velhos (pp.300, 303). Estes começam a falar do destino, ao qual os homens não podem fugir, e o Encenador vem libertar os Velhos do seu papel reduzido ao comentário, colocando-os a interagir com outra personagem, o próprio Encenador. São os Velhos do Coro que informam que agora Sófocles os colocava a "comentar o destino dos Labdácidas" e "a lamentar o peso da fatalidade". Simplesmente neste caso não é o papel do destino que António Pedro quer salientar; isso teria importância para o espectador do século V a.C., não para o espectador que assiste à peça em 1954. O que pretende aqui evidenciar é que o destino está na mão de cada um:

O Encenador:

Como todas as personagens da tragédia. Como todos nós. na
medida em que participamos um pouco do exagero que não pode deixar
de ter uma personagem de tragédia. $O$ Creonte, a Antígona, a Isménia de
cada um de nós, está nessa fome que vamos tendo, a cada passo, de
comer o pomo que foi negado a Adão... 9

9 Confrontar com o texto de Sófocles, vv. 472-473: "Indómita se revela a vontade da filha de indómito pai nascida. Não aprendeu a curvar-se perante a desgraça.” 
O final do acto segundo deveria terminar com o terceiro estásimo, que canta a invencibilidade do amor, suscitado pelo diálogo de Creonte e Hémon, mas esse só vai acontecer no terceiro acto, depois da conversa de Tirésias com Creonte e depois deste dizer que revoga o édito, pedindo que corram ao campo a sepultar os cadáveres. Esta intervenção dos Velhos (pp. 321, 323), à semelhança do terceiro estásimo sofocleano, trata do poder do amor, que é "capaz de alterar a face da terra".

Ainda antes, o Coro tem uma intervenção deveras importante ao dirigir-se a Creonte para que ouça Tirésias, a voz da sabedoria, pois só através dela o Homem se libertará. Entende-se, através destas palavras, uma crítica à tirania de Salazar que não ouve a razão e sobrepõe a sua própria vontade às leis da justiça.

Antes de proferir o que corresponderá ao quarto estásimo de Sófocles, o Coro intervém para comentar o silêncio de Eurídice "a sempre calada" (p. 235). Para o Coro, a rainha é a encarnação dos que sofrem em silêncio, na sombra, a protectora dos desamparados, dos perseguidos. A personagem da rainha é, nesta peça, muito mais activa do que no drama antigo. ${ }^{1011}$ É também muito mais emotiva, nomeadamente quando pega no punhal ensanguentado e o embala como se fosse o seu próprio filho. O seu silêncio, várias vezes apontado pelo Coro, pode levar-nos aos célebres silêncios da tragédia grega, tão comuns em Ésquilo, mas também presentes em Sófocles. Esses silêncios ${ }^{11}$ revestiam-se sempre de grande importância dramática, causando expectativa no público, prenunciando a desgraça e precediam uma saída que, normalmente, era seguida do suicídio. Assim acontece com a personagem de Sófocles e semelhante é a situação em António Pedro. Eurídice sai com o punhal nas mãos e, mais tarde, o Coro anuncia a sua morte, repetindo, mais uma vez, "pobre rainha Eurídice, sempre silenciosa e sempre boa!".

As réplicas que corresponderão ao quarto estásimo surgem depois do anúncio da morte de Antígona e de Hémon, onde se compara a heroína a "Níobe, filha de Tântalo, à roda de quem as pedras cresceram como hera". Refere ainda a sorte de Hémon, que vingou "em si a injustiça do pai" e prevê o fim triste de Eurídice.

10 No texto de Sófocles, Eurídice nem chega a ser uma personagem secundária importante. A sua participação começa e termina num breve aparecimento suscitado pelos rumores da desgraça que atingira a família. Sai depois, em silêncio, deixando preocupado o Mensageiro e o Coro.

11 Para um estudo dos silêncios em Sófocles, nomeadamente em Antígona, veja-se

M. Várzeas, Silêncios no teatro de Sófocles (Lisboa, Edições Cosmos 2001) 35, 49.

Faculdade de Letras | Universidade de Coimbra 
No que concerne ao quinto estásimo, é coinpletamente eliminado. Seria um tema incompreendido pelo espectador moderno. A cidade não é encarada da mesma forma que no século $\mathrm{V}$ a.C., não necessita de um deus que a venha libertar e curar, mas sim da queda de um regime opressor. Falta a este Coro a condenação final, António Pedro atribui-a a Tirésias, o cego que vê mais além e que aqui é a voz da sabedoria. Não foi um "deus ou um demónio" que conduziu os gestos de Creonte à sem razão, mas a "vaidade", o "orgulho" e a "obstinação", "que têm um preço de penas que é difícil de pagar".

Respondendo à questão se é o Coro um instrumento político, podemos concluir que sim, pois, ao longo da sua análise, sentimos que ele não está com Creonte, mas contra Creonte, o representante, na peça, da figura central do Estado Novo.

A concordância e adesão do Coro a Creonte, que no original também não é completamente voluntária e espontânea, é em António Pedro, apresentada por vozes anónimas. Estas no início dão vivas a Creonte e glorificam o rei: "Bravo, Creonte! Fala pela tua boca a voz da sabedoria!”, “E a justiça!”. É ainda uma voz que diz: "Glória ao teu nome, Creonte, rei de Tebas, herdeiro do trono de Laio!”. Em Sófocles, esta aclamação pertence ao Coro. Porque não faz o mesmo António Pedro? Ora, sendo o Coro uma figura importante na tragédia, o autor não o colocou em manifesta adesão ao tirano, pois isso seria dar relevo ao poder instituído, logo, o entusiasmo às palavras de Creonte vêm das vozes anónimas, as quais simbolizam o que não é importante, desvalorizando também, desta forma, os ideais da ditadura.

Assim como não vemos, por parte do Coro, essa manifestação de empatia, também não o vemos contra Antígona, que é o símbolo da luta pela liberdade; daí a recriminação de quem fosse contra o édito também não aparecer pela boca dos Velhos do Coro, mas por vozes: "E quem seria louco a ponto de fazê-lo?", “Se quem o tentar, morrerá!”, "E é justo que morra" (p. 277).

Penso poder afirmar que o Coro dos três Velhos, criado por António Pedro, é efectivamente uma arma de crítica ao regime do Estado Novo e pode mesmo representar os "velhos" ainda sobreviventes da I ${ }^{a}$ República Portuguesa, que continuavam a insurgir-se contra a ditadura de Salazar. Finalmente, este Coro de Velhos pode também funcionar como a voz do autor, que aparece na figura do Encenador para nos explicar alguns pormenores da tragédia, mas que, através do Coro, exerce a sua palavra contra a contextura sócio-política do seu tempo. 
Podemos concluir que a Antigona de António Pedro foi o palco para sonhar a liberdade e pensar a esperança.

\section{BIBLIOGRAFIA}

\section{Edições}

A. Pedro, Antigona. Glosa nova da Antigona de Sófocles em três actos e um prólogo, in A. Pedro, Teatro completo ( Lisboa, Imprensa Nacional - Casa da Moeda / Biblioteca Nacional 1981).

Sófocles, Antigona, trad, de M. H. Rocha Pereira (Coimbra, INIC 1984).

\section{Estudos}

F. A. L. Ferreira, «As Palavras e os Dias» de António Pedro 1909 1966. Dissertação de Mestrado em Literatura e Cultura Portuguesas. Época Contemporânea (Lisboa, 1996).

M. C. Fialho 'Sobre o trágico em Antigona de Sófocles', in Estudos sobre Antigona (Mem Martins, Editorial Inquérito 2000) 29- 50.

W. Jaeger, Paideia, trad, de A. M. Parreira (Lisboa, Editorial Aster 1979).

C. Morais, 'A Antigona de António Pedro: liberdades de uma glosa', in Máscaras Portuguesas de Antigona (Universidade de Aveiro 2001) 85-100.

V. Moreira 'O sistema jurídico-constitucional do «Estado Novo»', in História de Portugal, XII (Amadora, Clube Internacional do Livro) 212- 237.

A. Pedro, Escritos sobre Teatro (Porto, Angelus Novus \& Cotovia / TNSJ 2001).

C. Porto, O TEP e o Teatro em Portugal - Histórias e Imagens (Porto, Fundação Eng. António de Almeida 1997).

M. O. Pulquério, Problemática da tragédia sofocliana (Coimbra, INIC 1987).

J. G. T. Santos, 'A Natureza e a Lei: Reflexos de uma polémica em três textos da Grécia Antiga’, Estudos sobre Antigona (Mem Martins, Editorial Inquérito 2000) 77-111.

M. Várzeas, Silêncios no Teatro de Sófocles (Lisboa, Edições Cosmos 2001).

A. Ventura, 'A oposição ao Estado Novo', in História de Portugal, XIII (Amadora, Clube Internacional do Livro) 170-194. 